\title{
Granulomas of the liver
}

\author{
E. NeVILLE \\ M.B., M.R.C.P.
}

\author{
K. H. G. Piyasena* \\ M.B., M.R.C.P.
}

\author{
D. Geraint JAMES \\ M.D., F.R.C.P.
}

The Royal Northern Hospital, London and The Medical Unit, Royal Free Hospital, London $W C 1$

\begin{abstract}
Summary
The authors personally studied 138 patients with liver granulomas: seventy-five $(54 \%)$ had sarcoidosis, twenty-six $(19 \%)$ had primary biliary cirrhosis, twenty-three $(17 \%)$ had miscellaneous recognizable disorders and fourteen $(10 \%)$ were undiagnosed. The modes of presentation, the clinical, biochemical and radiological features are compared, and the course of each disease is followed. The undiagnosed group were frequently middle-aged men presenting with abdominal pain, fever and hepato-splenomegaly. The unsatisfactory term granulomatous hepatitis, if used, should be reserved for this undiagnosed residue until follow-up reveals a more definite aetiology.
\end{abstract}

SINCE aspiration needle biopsy has become commonplace, non-caseating liver granulomas are being reported with increasing frequency. These are characterized by follicles of epithelioid cells, macrocytes and giant cells with a surrounding rim of lymphocytes. They have been reported in $0.5-11 \%$ of various large series of liver biopsies (Klatskin and Yesner, 1950; Wagoner et al., 1953; Bunim et al., 1962; Hughes and Fox, 1972). Guckian and Perry (1966) classified liver granulomas into three categories-namely infection, hypersensitivity and unknown. Infections included viruses and parasites; hypersensitivity reactions included beryllium, phenylbutazone, sulphonamides, and erythema nodosum; and the idiopathic group included sarcoidosis, Hodgkin's disease and Wegener's granulomatosis. Since hepatic granulomas due to widely differing causes may be confusingly similar, there is no satisfactory histological classification. Some granulomas have distinctive features, e.g. the morphological appearance of primary biliary cirrhosis, the caseation of tuberculosis, the rare finding of mycobacteria on staining, or the presence of a schistosome egg. Granulomas in sarcoidosis retain their reticulin framework compared with those of tuberculosis (James and Thomson, 1955; Scheuer, 1973a).

\footnotetext{
* Present address: Department of Medicine, Emory University, Atlanta, Georgia, U.S.A.
}

In a personally studied series of 138 patients with miliary hepatic granulomas, the authors analysed the clinical, radiological and immunological data most helpful in defining the aetiology and thereby the prognosis, and have been particularly interested to discern whether granulomatous hepatitis is a distinguishable condition.

\section{Patients}

The patients had been referred originally to the Sarcoidosis Clinic of the Royal Northern or to the Royal Free Hospital over a 10-year period, with possible sarcoidosis or primary biliary cirrhosis (PBC) so the series is selective.

In the absence of a satisfactory classification of hepatic granulomas, the 138 patients were divided into four groups, comprising seventy-five patients with sarcoidosis, twenty-six with PBC, twenty-three patients with miscellaneous recognizable disorders, and fourteen patients in whom no cause for the hepatic granulomas could be established (Table 1).

TABle 1. One hundred and thirty-eight patients with hepatic granulomas allocated into one of four groups

\begin{tabular}{lcc}
\hline \multicolumn{1}{c}{ Aetiology } & No. & $\%$ \\
\hline Sarcoidosis & 75 & 54 \\
Primary biliary cirrhosis & 26 & 19 \\
Miscellaneous & 23 & 17 \\
Unknown & 14 & 10 \\
Total & 138 & 100 \\
\hline
\end{tabular}

\section{Age and sex at presentation}

Fifty-one of seventy-five $(68 \%)$ patients with sarcoidosis presented in the $20-40$ age group and there was no sex predilection, whereas twenty-one of twenty-six (81\%) PBC patients were aged 30-50 and all but one were women. The patients with miscellaneous disorders were of both sexes, females predominating, whereas the undiagnosed group were predominantly men over 50 years old (Table 2 ). 
TABLE 2. Age and sex of 138 patients with hepatic granulomas at presentation

\begin{tabular}{lrrrrrr}
\hline & \multicolumn{5}{c}{ Age at onset (\%) } & Female \\
\cline { 2 - 6 } \multicolumn{1}{c}{ Group } & $<20$ & $21-30$ & $31-40$ & $41-50$ & $>50$ & $(\%)$ \\
\hline Sarcoidosis & 5 & 43 & 25 & 19 & 8 & 49 \\
PBC & 0 & 19 & 57 & 24 & 0 & 96 \\
Miscellaneous & 18 & 22 & 4 & 22 & 34 & 65 \\
Unknown & 0 & 14 & 14 & 7 & 65 & 43 \\
Overall & 6 & 32 & 27 & 19 & 16 & 60 \\
\hline
\end{tabular}

\section{Mode of presentation}

The patients with hepatic granulomas due to sarcoidosis presented in the usual manner with a respiratory, cutaneous or ophthalmic onset (Table 3). Hepatic granulomas had been sought to confirm the clinical diagnosis.

TABLE 3. Mode of presentation of seventy-five patients with sarcoidosis known to have hepatic granulomas

\begin{tabular}{lrl}
\hline \multicolumn{1}{c}{ Presentation } & No. & $\%$ \\
\hline Respiratory & 25 & 34 \\
Erythema nodosum or other skin lesions & 14 & 18 \\
Uveitis & 7 & 10 \\
Alimentary or vague general symptoms & 21 & 28 \\
\hline
\end{tabular}

Similarly the patients with hepatic granulomas due to $\mathrm{PBC}$ presented in the same fashion as any patient with PBC. Pruritus, jaundice and hepatomegaly were presenting features in two-thirds of patients, abdominal pain and splenomegaly in one-third and xanthomas in one-fifth of patients (Table 4).

TABLE 4. Modes of presentation of twenty-six patients with PBC known to have hepatic granulomas

\begin{tabular}{lcc}
\hline \multicolumn{1}{c}{ Features } & No. & $\%$ \\
\hline Pruritus & 18 & 69 \\
Jaundice & 17 & 65 \\
Hepatomegaly & 17 & 65 \\
Splenomegaly & 10 & 38 \\
Abdominal pain & 9 & 34 \\
Xanthomas & 5 & 19 \\
\hline
\end{tabular}

Twenty-three patients had hepatic granulomas associated with a variety of diseases. Many were hepato-biliary disorders and others formed a heterogeneous group (Table 5). They tended to present with hepatomegaly $(56 \%)$ and splenomegaly $(39 \%)$ which undoubtedly led to aspiration liver biopsy and the finding of hepatic granulomas.

The fourteen undiagnosed patients all had liver biopsies in the course of investigation. Seven of the fourteen $(50 \%)$ had vague abdominal pain and six were febrile, thus presenting as a pyrexia of unknown origin. Three $(21 \%)$ had lost weight but none had pruritus (Table 6). Of the seventy-five patients with sarcoidosis very few had similar symptomatology: only four patients $(5 \%)$ had abdominal pain, ten patients $(13 \%)$ were febrile and eleven patients $(14 \%)$ had lost weight. Of the patients with PBC, $34 \%$ had abdominal pain but only two of twenty-six $(7 \%)$ were pyrexial and had lost weight. Pruritus in eighteen $(69 \%)$ patients with $\mathrm{PBC}$ was a significant distinguishing feature from the other group. In the miscellaneous group, two patients $(9 \%)$ had pruritus, five $(22 \%)$ had abdominal pain and six $(26 \%)$ weight loss, but only four $(17 \%)$ were febrile.

TABLE 5. Miscellaneous causes of hepatic granulomas in twenty-three patients

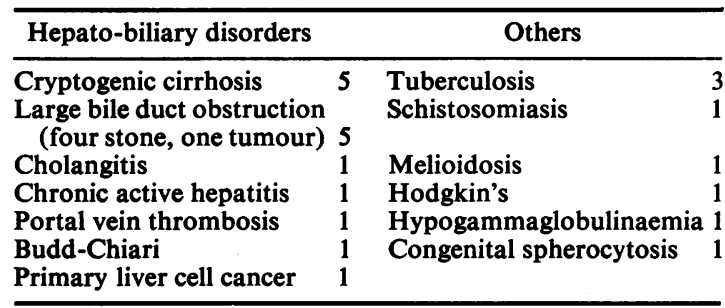

TABle 6. Presenting symptomatology of 138 patients with hepatic granulomas

\begin{tabular}{lcccc}
\hline \multicolumn{1}{c}{ Group } & $\begin{array}{c}\text { Abdominal } \\
\text { pain } \\
(\%)\end{array}$ & $\begin{array}{c}\text { Fever } \\
(\%)\end{array}$ & $\begin{array}{c}\text { Weight } \\
\text { loss } \\
(\%)\end{array}$ & $\begin{array}{c}\text { Pruritus } \\
(\%)\end{array}$ \\
\hline Sarcoidosis & 5 & 13 & 14 & 0 \\
PBC & 34 & 7 & 7 & 69 \\
Miscellaneous & 22 & 17 & 26 & 9 \\
Unknown & 50 & 43 & 21 & 0 \\
Overall & 18 & 16 & 16 & 15 \\
\hline
\end{tabular}

The fourteen undiagnosed patients remained an enigma, possibly because the physical signs were not so distinctive (Table 7). The number of patients with hepatomegaly $(57 \%)$, splenomegaly $(29 \%)$ and jaundice $(14 \%)$ was very similar to the overall figures. On examination the sarcoidosis group were distinguishable by the signs already mentioned but also twenty-five patients $(33 \%)$ had hepatomegaly and twenty-one $(28 \%)$ had splenomegaly. None was

Table 7. Presenting signs in 138 patients with hepatic granulomas

\begin{tabular}{lcccc}
\hline \multicolumn{1}{c}{ Group } & $\begin{array}{c}\text { Liver } \\
(\%)\end{array}$ & $\begin{array}{c}\text { Spleen } \\
(\%)\end{array}$ & $\begin{array}{c}\text { Jaundice } \\
(\%)\end{array}$ & $\begin{array}{c}\text { Lymph nodes } \\
(\%)\end{array}$ \\
\hline Sarcoidosis & 33 & 28 & 0 & 16 \\
PBC & 65 & 38 & 65 & 0 \\
Miscellaneous & 56 & 39 & 26 & 13 \\
Unknown & 57 & 29 & 14 & 0 \\
Overall & 46 & 32 & 18 & 11 \\
\hline
\end{tabular}


TABLE 8. Liver function tests in patients with hepatic granulomas

\begin{tabular}{|c|c|c|c|c|c|c|c|c|c|c|c|c|c|c|c|}
\hline \multirow[b]{2}{*}{ Group } & \multicolumn{3}{|c|}{$\begin{array}{l}\text { Aspartate } \\
\text { transaminase } \\
(>20 \text { i.u./l) }\end{array}$} & \multicolumn{3}{|c|}{$\begin{array}{c}\text { Alkaline } \\
\text { phosphatase } \\
(>13 \mathrm{~K} . \text { A. u) }\end{array}$} & \multicolumn{3}{|c|}{$\begin{array}{c}\text { Bilirubin } \\
(>2.0 \mathrm{mg} / 100 \mathrm{ml})\end{array}$} & \multicolumn{3}{|c|}{$\left(<\begin{array}{l}\text { Albumin } \\
3.0 \mathrm{~g} / 100 \mathrm{ml})\end{array}\right.$} & \multicolumn{3}{|c|}{$\left(>\quad \begin{array}{l}\text { Globulin } \\
(>5 \mathrm{~g} / 100 \mathrm{ml})\end{array}\right.$} \\
\hline & No. & Total & $\%$ & No. & Total & $\%$ & No. & Total & $\%$ & No. & Total & $\%$ & No. & Total & $\%$ \\
\hline $\begin{array}{l}\text { Sarcoidosis } \\
\text { PBC } \\
\text { Miscellaneous } \\
\text { Unknown }\end{array}$ & $\begin{array}{r}14 \\
26 \\
10 \\
6\end{array}$ & $\begin{array}{l}24 \\
26 \\
17 \\
11\end{array}$ & $\begin{array}{r}58 \\
100 \\
59 \\
55\end{array}$ & $\begin{array}{r}24 \\
26 \\
15 \\
9\end{array}$ & $\begin{array}{l}44 \\
26 \\
19 \\
14\end{array}$ & $\begin{array}{r}55 \\
100 \\
79 \\
64\end{array}$ & $\begin{array}{r}0 \\
17 \\
7 \\
1\end{array}$ & $\begin{array}{l}35 \\
26 \\
21 \\
12\end{array}$ & $\begin{array}{r}0 \\
65 \\
33 \\
8\end{array}$ & $\begin{array}{l}3 \\
8 \\
2 \\
3\end{array}$ & $\begin{array}{l}69 \\
26 \\
19 \\
13\end{array}$ & $\begin{array}{r}4 \\
30 \\
11 \\
23\end{array}$ & $\begin{array}{l}30 \\
16 \\
13 \\
10\end{array}$ & $\begin{array}{l}69 \\
26 \\
19 \\
14\end{array}$ & $\begin{array}{l}43 \\
61 \\
68 \\
71\end{array}$ \\
\hline Overall & 66 & 78 & 85 & 64 & 103 & 62 & 25 & 94 & 27 & 16 & 127 & 13 & 69 & 128 & 54 \\
\hline
\end{tabular}

jaundiced. The number of patients with hepatomegaly and splenomegaly due to PBC and in the miscellaneous group was very similar, but $65 \%$ of patients with PBC were jaundiced compared with $26 \%$ in the miscellaneous group and $18 \%$ overall.

\section{Investigations}

Biochemistry

Biochemical or liver function test abnormalities were commonly found in association with PBC and the hepato-biliary disorders in the miscellaneous group. The aspartate transaminase was the most frequently abnormal test, being elevated in $85 \%$ of patients overall (Table 8). The alkaline phosphatase was elevated in $62 \%$ overall and bilirubin in only $27 \%$. The serum albumin was reduced in only $13 \%$ of cases overall, while serum globulins were elevated in about $50 \%$ of the patients. In the undiagnosed group alkaline phosphatase levels were above 13 King Armstrong units in $64 \%$ of patients, whereas aspartate transaminase was elevated in only $55 \%$.

Serum calcium levels were elevated above 11.0 $\mathrm{mg} / 100 \mathrm{ml}$ in $13 \%$ of the sarcoidosis patients and in two of nine patients in the undiagnosed group. Hypocalcaemia was found in $18 \%$ of patients with PBC, in association with steatorrhoea. Hypercholesterolaemia occurred in eighteen of twenty patients with $\mathrm{PBC}(90 \%)$ but in no other groups.

\section{Radiography}

An abnormal chest radiograph was found in 55\% of patients overall, predominantly in the sarcoidosis group $(84 \%$ ) (Table 9). Only one of the undiagnosed patients had a significant radiographic abnormalitya pleural effusion associated with a calcified left hilar gland. Three patients with $\mathrm{PBC}$ had radiographic changes, namely: patchy areas of linear and nodular shadowing in both lung fields, calcified foci in the apices and pleural thickening respectively.

\section{Skin tests}

The Kveim-Siltzbach skin test was positive in $72 \%$ of patients with sarcoidosis but in none of the other groups. Tuberculin testing was negative in $72 \%$ overall and in nine of twelve patients in the undiagnosed group (Table 10).

\section{Antibodies}

Autoantibodies were most frequently found where hepatic granulomas were due to PBC (Table 11) The antimitochrondrial antibody (AMA) test was positive in $79 \%$ of these patients. It was also positive in one of twenty-three patients with sarcoidosis, occurring in a 45-year-old woman 8 years after her acute sarcoidosis had become inactive. She still had abnormal liver function tests, but a further liver biopsy was not done. AMA were present on two occasions at a titre of 1 in 64 . Smooth muscle antibody (SMA) was found in two of four patients and anti-nuclear antibody (ANA) in two of six patients in the undiagnosed group.

\section{Haematology}

Anaemia and leucopenia were infrequent in all groups; three patients in the undiagnosed group had a neutrophil leucocytosis.

TABLE 9. Abnormal chest radiographs in 138 patients with hepatic granulomas

\begin{tabular}{lrr}
\hline \multicolumn{1}{c}{ Group } & No. & $\%$ \\
\hline Sarcoidosis & 63 & 84 \\
PBC & 3 & 11 \\
Miscellaneous & 8 & 35 \\
Unknown & 2 & 14 \\
Overall & 76 & 55 \\
\hline
\end{tabular}

TABLE 10. Tuberculin testing in patients with hepatic granulomas

\begin{tabular}{lccc}
\hline \multicolumn{1}{c}{ Group } & $\begin{array}{c}\text { No. } \\
\text { tested }\end{array}$ & $\begin{array}{c}\text { Mantoux } \\
\text { negative }\end{array}$ & $\%$ \\
\hline Sarcoidosis & 70 & 52 & 74 \\
PBC & 12 & 9 & 75 \\
Miscellaneous & 13 & 6 & 46 \\
Unknown & 12 & 9 & 75 \\
Overall & 106 & 76 & 72 \\
\hline
\end{tabular}


TABLE 11. Auto-antibodies in patients with liver granulomas

\begin{tabular}{|c|c|c|c|c|c|c|c|c|c|}
\hline \multirow[b]{2}{*}{ Group } & \multicolumn{3}{|c|}{ AMA } & \multicolumn{3}{|c|}{ SMA } & \multicolumn{3}{|c|}{ ANA } \\
\hline & No. & Total & $\%$ & No. & Total & $\%$ & No. & Total & $\%$ \\
\hline $\begin{array}{l}\text { Sarcoidosis } \\
\text { PBC } \\
\text { Miscellaneous } \\
\text { Unknown }\end{array}$ & $\begin{array}{r}1 \\
19 \\
0 \\
0\end{array}$ & $\begin{array}{r}23 \\
24 \\
3 \\
5\end{array}$ & $\begin{array}{r}4 \\
79 \\
0 \\
0\end{array}$ & $\begin{array}{l}0 \\
6 \\
2 \\
2\end{array}$ & $\begin{array}{r}2 \\
13 \\
5 \\
4\end{array}$ & $\begin{array}{r}0 \\
22 \\
40 \\
50\end{array}$ & $\begin{array}{l}0 \\
5 \\
1 \\
2\end{array}$ & $\begin{array}{r}6 \\
18 \\
8 \\
6\end{array}$ & $\begin{array}{r}0 \\
27 \\
12 \\
33\end{array}$ \\
\hline Overall & 20 & 55 & 36 & 10 & 24 & 41 & 8 & 38 & 21 \\
\hline
\end{tabular}

\section{Course of the disease}

Of the seventy-five patients with hepatic granulomas due to sarcoidosis, forty-six have been followed from 1 to 14 years-thirty-five $(76 \%)$ showed complete resolution, eight $(17 \%)$ have chronic, persistent sarcoidosis, and two have died from unrelated diseases. Repeat aspiration liver biopsies were normal in three of four patients but one patient still showed hepatic granulomas 8 years later. He developed presinusoidal portal hypertension 17 years after the onset of his sarcoidosis and underwent a successful portocaval anastomosis 21 years after the onset. The other patients had lapsed from follow-up, usually at a stage when the disease was inactive.

In the patients with PBC, the liver biopsies were staged according to Scheuer (1973b). The granulomas tended to be present at the earlier stages of the disease. Fifteen patients had stage 1, seven had stage 2 , three had stage 3 and one had the late stage 4 histological change. In a 1-10 year follow-up period, eight $(30 \%)$ had died, three $(12 \%)$ had portal hypertension and all had progressively abnormal liver function tests.

The course and prognosis of the twenty-three patients in the miscellaneous group was that of their primary diseases (Table 5).

Of the fourteen patients with no diagnosed cause for their liver granulomas one died of a cerebrovascular accident, five recovered spontaneously within 2-4 years and one with the help of anti-tuberculous chemotherapy. One has been lost to follow-up and the remaining seven are still under out-patient observation. In all these seven patients, sarcoidosis, PBC and other recognizable hepatobiliary disorders have been excluded. No causal infective agent has been identified. The duration of follow-up makes reticulosis unlikely. Alcoholic hepatitis is unlikely for it would have been recognized by liver biopsy.

\section{Discussion}

There are numerous well defined causes of hepatic granulomas. Depending upon the selection of patients, they could be due to sarcoidosis, PBC, brucellosis, tuberculosis, or various hepatobiliary disorders.
When all well defined causes of hepatic granulomas have been excluded there still remains an obscure group of patients with hepatic granulomas, who are frequently middle-aged men presenting with abdominal pain, fever and hepatosplenomegaly. This clinical picture could be called granulomatous hepatitis though the term has also been applied to patients with fever who are found to have hepatic granulomas. Where the accompanying febrile illness is selflimiting (Eliakim et al., 1968), it seems likely that there is an infective aetiology, possibly viral, but this possibility remains unconfirmed. Simon and Wolff (1973) described thirteen patients with prolonged fever and liver granulomas; two developed malignancies, one responded to anti-tuberculous chemotherapy, and nine of ten responded to corticosteroids. Israel and Goldstein (1973) studied thirty patients with normal chest radiographs and non-caseating hepatic granulomas, sixteen of whom may have had sarcoidosis, one died of Hodgkin's disease and another of malignant melanoma. One patient still had granulomas despite 2 years of anti-tuberculous chemotherapy, whereas the others recovered spontaneously or with steroids. Guckian and Perry (1966, 1968) observed thirteen undiagnosed patients; with adequate follow-up they recognized sarcoidosis in three, tuberculosis in two, $Q$ fever in one and syphilis in one.

The sarcoid granuloma, wherever it occurs, represents an antigen-antibody battleground. In PBC it is alongside the cholangioles suggesting bile duct antigen. In multisystem sarcoidosis the site of the granuloma may be initiated by the deposition of a circulating immune complex. There is some evidence that circulating immune complexes are present in acute sarcoidosis (Hedfors and Norberg, 1974; James, Neville and Walker, 1974). Depression of delayed hypersensitivity must also be explained as $72 \%$ of the authors' patients with hepatic granulomas were anergic to tuberculin. The $\mathrm{T}$ lymphocytes may be the initial line of defence against the antigen and, when they are depleted, granulomas form.

The significance of finding a hepatic granuloma depends on many features other than the granuloma itself. Diagnosis must be linked to the clinical picture and the results of X-ray, blood and skin tests, and 
microbiology; the cause is then recognized in $90 \%$ of patients. The unsatisfactory term granulomatous hepatitis, if used, should be reserved for the undiagnosed residue until follow-up reveals a more definitive aetiology.

\section{Acknowledgments}

The Clinical Research Unit of the former North-West Metropolitan Regional Hospital Board gave generous financial support. We are grateful to the new Camden and Islington Area Health Authority for continuing this support to Dr E. Neville.

We are also grateful to the Davis fund of the Royal Free Hospital for financial support to Dr K. H. G. Piyasena.

This study has been possible thanks to the close co-operation of Professor S. Sherlock and Dr P. J. Scheuer at the Royal Free Hospital.

\section{References}

Bunim, J.J., Kimberg, D.V., Thomas, L.B., van ScotT, E.J. \& Klatskin, G. (1962) The syndrome of sarcoidosis, psoriasis and gout. Annals of Internal Medicine, 57, 1018.

Eliakim, M., EISENBERG, S., LEVIJ, I.S. \& SACKS, T.G. (1968) Granulomatous hepatitis accompanying a self-limiting febrile disease. Lancet, i, 1348.

Guckian, J.C. \& PerRy, J.E. (1966) Granulomatous hepatitis. An analysis of 63 cases and review of the literature. Annals of Internal Medicine, 65, 1081.
Guckian, J.C. \& Perry, J.E. (1968) Granulomatous hepatitis of unknown etiology, an etiologic and functional evaluation. American Journal of Medicine, 44, 207.

Hedfors, E. \& NoRbERG, R. (1974) Evidence for circulating immune complexes in sarcoidosis. Clinical and Experimental Immunology, 16, 493.

Hughes, M. \& Fox, H. (1972) A histological analysis of granulomatous hepatitis. Journal of Clinical Pathology, 25, 817.

ISRAEL, H.L. \& Goldstein, R.A. (1973) Hepatic granulomatosis and sarcoidosis. Annals of Internal Medicine, 79, 669.

JAmes, D.G. \& Thomson, D.A. (1955) The Kveim test in sarcoidosis. Quarterly Journal of Medicine, 24, 49.

JAmes, D.G., Neville, E. \& Walker, A.N. (1975) Immunology of sarcoidosis. American Journal of Medicine (in press).

Klatskin, G. \& Yesner, R. (1950) Hepatic manifestations of sarcoidosis and other granulomatous diseases. A study based on histological examination of tissue obtained by needle biopsy of liver. Yale Journal of Biology and Medicine, 23, 207.

SCHEUER, P.J. (1973a) Liver Biopsy Interpretation, 2nd edn, p. 133. Baillière Tindall, London.

SCHEUER, P.J. (1973b) Liver Biopsy Interpretation, 2nd edn, p. 33. Baillière Tindall, London.

Simon, H.B. \& WoLfF, S.M. (1973) Granulomatous hepatitis and prolonged fever of unknown origin: a study of 13 patients. Medicine, 52, 1.

WAGONER, G.P., ANton, A.T., Gall, E.A. \& Schiff, L. (1953) Needle biopsy of the liver. VIII. Experiences with hepatic granulomas. Gastroenterology, 25, 487. 